\title{
Approximating fixed points for a reversible semigroup of Lipschitzian mappings in a smooth Banach space
}

\author{
Hossein Piri ${ }^{1}$ and Poom Kumam² ${ }^{2 *}$
}

\section{"Correspondence:}

poom.kum@kmutt.ac.th

${ }^{2}$ Department of Mathematics,

Faculty of Science, King Mongkut's

University of Technology Thonburi (KMUTT), Bang Mod, Thrung Khru,

Bangkok, 10140, Thailand

Full list of author information is

available at the end of the article

\begin{abstract}
In this paper, we approximate a fixed point of the semigroup $\varphi=\left\{T_{s}: S \in S\right\}$ of Lipschitzian mappings from a nonempty compact convex subset $C$ of a smooth Banach space $E$ into $C$ with a uniform Lipschitzian condition and with respect to a finite family of sequences $\left\{\mu_{i, n}\right\}_{i=1, n=1}^{m, \infty}$ of left strong regular invariant means defined on an appropriate invariant subspace of $1^{\infty}(S)$. Our result extends the main results announced by several others.
\end{abstract}

MSC: 47H09; 47H10;47J25

Keywords: smooth Banach space; asymptotically nonexpansive semigroup; reversible semigroup; invariant mean

\section{Introduction}

Let $E$ be a real Banach space with the topological dual $E^{*}$, and let $C$ be a nonempty closed and convex subset of $E$. Recall that a mapping $T$ of $C$ into itself is said to be

(1) Lipschitzian with Lipschitz constant $l>0$ if

$$
\|T x-T y\| \leq l\|x-y\|, \quad \forall x, y \in C .
$$

(2) nonexpansive if

$$
\|T x-T y\| \leq\|x-y\|, \quad \forall x, y \in C .
$$

(3) asymptotically nonexpansive if there exists a sequence $\left\{l_{n}\right\}$ of positive numbers such that $\lim _{n \rightarrow \infty} l_{n}=1$ and

$$
\left\|T^{n} x-T^{n} y\right\| \leq l_{n}\|x-y\|, \quad \forall x, y \in C .
$$

A semigroup $S$ is called left reversible if any two closed right ideals of $S$ have non-void intersection, i.e., $a S \cap b S \neq \emptyset$ for $a, b \in S$. In this case, $(S, \preceq)$ is a directed set when the binary relation $\preceq$ on $S$ is defined by $a \preceq b$ if and only if $a S \supset b S$ for $a, b \in S$.

Notation Throughout the rest of this paper, $S$ will always denote a left reversible semigroup with an identity $e$.

○2013 Piri and Kumam; licensee Springer. This is an Open Access article distributed under the terms of the Creative Commons Attribution License (http://creativecommons.org/licenses/by/2.0), which permits unrestricted use, distribution, and reproduction in any medium, provided the original work is properly cited. 
In [1], Lau et al. studied iterative schemes for approximating a fixed point of the semigroup $\varphi=\{T(s): s \in S\}$ of nonexpansive mappings on a nonempty compact convex subset $C$ of a smooth (and strictly convex) Banach space and introduced the following iteration process. Let $x_{1}=x \in C$ and

$$
x_{n+1}=\alpha_{n} x_{n}+\left(1-\alpha_{n}\right) T_{\mu_{n}} x_{n}, \quad n \geq 1,
$$

where $\left\{\mu_{n}\right\}_{n=1}^{\infty}$ is a sequence of left strong regular invariant means defined on an appropriate invariant subspace of $l^{\infty}(S)$.

$\varphi=\{T(s): s \in S\}$ is called a representation of $S$ as a Lipschitzian mapping on $C$ with Lipschitz constant $\{l(s): s \in S\}$ if $T(s)$ is a Lipschitzian with Lipschitz constant $l(s)$ for each $s \in S, T(s t)=T(s) T(t)$ for each $t, s \in S$ and $T(e)=I . \varphi$ is called an asymptotically nonexpansive semigroup on $C$ if $\varphi$ is a representation of $S$ as a Lipschitzian mapping on $C$ with Lipschitz constant $\{l(s) ; s \in s\}$ and $\lim _{s} l(s) \leq 1$.

In 2008, Saeidi proved the following theorem.

Theorem 1.1 [2] Let $S$ be a left reversible semigroup and $\varphi=\left\{T_{s}: s \in S\right\}$ be a representation of $S$ as a Lipschitzian mapping from a nonempty compact convex subset $C$ of a smooth Banach space $E$ into $C$, with uniform Lipschitzian constant $\lim _{s} K(s) \leq 1$, and let $f$ be an $\alpha$-contraction on $C$ for some $0<\alpha<1$. Let $X$ be a left invariant $\varphi$-stable subspace of $L^{\infty}(\varphi)$ containing 1 , let $\left\{\mu_{n}\right\}_{n=1}^{\infty}$ be a sequence of left strong regular invariant means defined on $X$ such that $\lim _{n \rightarrow \infty}\left\|\mu_{n+1}-\mu_{n}\right\|=0$, and let $\left\{c_{n}\right\}_{n=1}^{\infty}$ be a sequence defined by

$$
c_{n}=\sup _{x, y \in C}\left(\left\|T_{\mu_{n}} x-T_{\mu_{n}} y\right\|-\|x-y\|\right), \quad n \geq 1
$$

Let $\left\{\alpha_{n}\right\}_{n=1}^{\infty},\left\{\beta_{n}\right\}_{n=1}^{\infty}$ and $\left\{\gamma_{n}\right\}_{n=1}^{\infty}$ be sequences in $(0,1)$ such that

(C) $\alpha_{n}+\beta_{n}+\gamma_{n}=1, n \geq 1$,

$\left(\mathrm{C}_{2}\right) \lim _{n \rightarrow \infty} \alpha_{n}=0$,

$\left(\mathrm{C}_{3}\right) \sum_{n=1}^{\infty} \alpha_{n}=\infty$,

$\left(C_{4}\right) \quad 0<\liminf _{n \rightarrow \infty} \beta_{n} \leq \limsup _{n \rightarrow \infty} \beta_{n}<1$,

$\left(\mathrm{C}_{5}\right) \limsup _{n \rightarrow \infty} \frac{c_{n}}{\alpha_{n}} \leq 0$.

If $\left\{x_{n}\right\}_{n=1}^{\infty}$ is a sequence generated by $x_{1} \in C$ and

$$
x_{n+1}=\alpha_{n} f\left(x_{n}\right)+\beta_{n} x_{n}+\gamma_{n} T_{\mu_{n}} x_{n}, \quad n \geq 1,
$$

then the sequence $\left\{x_{n}\right\}_{n=1}^{\infty}$ converges strongly to some $z \in \operatorname{Fix}(\varphi)$, the set of common fixed points of $\varphi$, which is the unique solution of the variational inequality

$$
\langle(f-I) z, J(y-z)\rangle \leq 0, \quad \forall y \in \operatorname{Fix}(\varphi)
$$

Equivalently, one has $z=P f z$, where $P$ is the unique sunny nonexpansive retraction of $C$ onto $F(\varphi)$.

In 2007, Zhang et al. [3] introduced the following composite iteration scheme:

$$
\left\{\begin{array}{l}
y_{n}=\beta_{n} x_{n}+\left(1-\beta_{n}\right) T t_{n} x_{n}, \\
x_{n+1}=\alpha_{n} u+\left(1-\alpha_{n}\right) y_{n},
\end{array}\right.
$$


where $\{T(t): t \geq 0\}$ is a nonexpansive semigroup from $C$ to $C, u$ is an arbitrary (but fixed) element in $C,\left\{\alpha_{n}\right\} \subset(0,1)$ and $\left\{\beta_{n}\right\} \subset[0,1],\left\{t_{n}\right\} \subset \mathbb{R}^{+}$, and proved some strong convergence theorems of an explicit composite iteration scheme for nonexpansive mappings in the framework of a reflexive Banach space with a uniformly Gâteaux differentiable norm, uniformly smooth Banach space and uniformly convex Banach space with a weakly continuous normalized duality mapping.

Motivated and inspired by Zhang et al. [3] and Saeidi [2], Katchang and Kumam proved the following theorem.

Theorem 1.2 [4] Let $S$ be a left reversible semigroup, and let $\varphi=\left\{T_{s}: s \in S\right\}$ be a representation of $S$ as a Lipschitzian mapping from a nonempty compact convex subset $C$ of a smooth Banach space $E$ into $C$, with uniform Lipschitzian constant $\lim _{s} K(s) \leq 1$, and let $f$ be an $\alpha$-contraction on $C$ for some $0<\alpha<1$. Let $X$ be a left invariant $\varphi$-stable subspace of $L^{\infty}(\varphi)$ containing 1 , let $\left\{\mu_{n}\right\}_{n=1}^{\infty}$ be a sequence of left strong regular invariant means defined on $X$ such that $\lim _{n \rightarrow \infty}\left\|\mu_{n+1}-\mu_{n}\right\|=0$, and let $\left\{c_{n}\right\}_{n=1}^{\infty}$ be a sequence defined by

$$
c_{n}=\sup _{x, y \in C}\left(\left\|T_{\mu_{n}} x-T_{\mu_{n}} y\right\|-\|x-y\|\right), \quad n \geq 1 .
$$

Let $\left\{\alpha_{n}\right\}_{n=1}^{\infty},\left\{\beta_{n}\right\}_{n=1}^{\infty},\left\{\gamma_{n}\right\}_{n=1}^{\infty}$ and $\left\{\delta_{n}\right\}_{n=1}^{\infty}$ be sequences in $(0,1)$ such that

(C) $\alpha_{n}+\beta_{n}+\gamma_{n}=1, n \geq 1$,

$\left(C_{2}\right) \lim _{n \rightarrow \infty} \alpha_{n}=0$,

(C) $\sum_{n=1}^{\infty} \alpha_{n}=\infty$,

$\left(\mathrm{C}_{4}\right) \quad 0<\liminf _{n \rightarrow \infty} \beta_{n} \leq \lim \sup _{n \rightarrow \infty} \beta_{n}<1$,

$\left(C_{5}\right) \lim \sup _{n \rightarrow \infty} \frac{c_{n}}{\alpha_{n}} \leq 0$,

$\left(\mathrm{C}_{6}\right) \lim _{n \rightarrow \infty} \delta_{n}=0$.

If $\left\{x_{n}\right\}_{n=1}^{\infty}$ is a sequence generated by $x_{1} \in C$ and

$$
\left\{\begin{array}{l}
y_{n}=\delta_{n} x_{n}+\left(1-\delta_{n}\right) T_{\mu_{n}} x_{n}, \\
x_{n+1}=\alpha_{n} f\left(x_{n}\right)+\beta_{n} x_{n}+\gamma_{n} y_{n}, \quad n \geq 1,
\end{array}\right.
$$

then the sequence $\left\{x_{n}\right\}_{n=1}^{\infty}$ converges strongly to some $z \in \operatorname{Fix}(\varphi)$, which is the unique solution of the variational inequality

$$
\langle(f-I) z, J(y-z)\rangle \leq 0, \quad \forall y \in F(\varphi) .
$$

Equivalently, one has $z=P f z$, where $P$ is the unique sunny nonexpansive retraction of $C$ onto $F(\varphi)$.

Recently, many authors studied fixed point results for a nonlinear semigroup mapping, for example, [5-8].

In this paper, motivated and inspired by Qianglian et al. [9], Lau et al. [1], Zhang et al. [3], Saeidi [2], Katchang and Kumam [4], Sunthrayuth and Kumam [10,11] and Wattanawitoon and Kumam [12], we introduce the composite explicit viscosity iterative schemes as 
follows:

$$
\begin{aligned}
& x_{n+1}=\alpha_{n} f\left(y_{1, n}\right)+\beta_{n} x_{n}+\gamma_{n} T_{\mu_{1, n}} y_{1, n}, \\
& y_{i, n}=\delta_{i, n} y_{i+1, n}+\left(I-\delta_{i, n}\right) T_{\mu_{i, n}} y_{i+1, n}, \quad i=1,2, \ldots, m, \\
& y_{m+1, n}=x_{n}
\end{aligned}
$$

for an asymptotically nonexpansive semigroup $\varphi=\left\{T_{s}: s \in S\right\}$ on a compact convex subset $C$ of a smooth Banach space $E$ with respect to a finite family of left regular sequences $\left\{\mu_{i, n}\right\}_{i=1, n=1}^{m, \infty}$ of invariant means defined on an appropriate invariant subspace of $l^{\infty}(S)$. We prove, under certain appropriate assumptions on the sequences $\left\{\alpha_{n}\right\}_{n=1}^{\infty},\left\{\beta_{n}\right\}_{n=1}^{\infty},\left\{\gamma_{n}\right\}_{n=1}^{\infty}$ and $\left\{\delta_{n}\right\}_{i=1, n=1}^{m, \infty}$, that $\left\{x_{n}\right\}_{n=1}^{\infty}$ and $\left\{y_{n}\right\}_{i=1, n=1}^{m, \infty}$ defined by (4) converge strongly to $z \in \operatorname{Fix}(\varphi)$, which is the unique solution of the variational inequality

$$
\langle(f-I) z, J(y-z)| \leq 0, \quad \forall y \in \operatorname{Fix}(\varphi) .
$$

Our result improves and extends many previous results (e.g., $[1,2,4,13-15]$ and many others).

\section{Preliminaries}

Let $E^{*}$ be the topological dual of a real Banach space $E$. The value of $j \in E^{*}$ at $x \in E$ will be denoted by $\langle x, j\rangle$ or $j(x)$. With each $x \in E$, we associate the set

$$
J(x)=\left\{j \in E^{*}:\langle x, j\rangle=\|x\|^{2}=\|j\|^{2}\right\} .
$$

Using the Hahn-Banach theorem, it is immediately clear that $J(x) \neq \phi$ for each $x \in E$. The multi-valued mapping $J$ from $E$ into $E^{*}$ is said to be the (normalized) duality mapping. A Banach space $E$ is said to be smooth if the duality mapping $J$ is single-valued. As is well known, the duality mapping is norm to weak-star continuous when $E$ is smooth, see [16].

Let $B(S)$ be the Banach space of all bounded real-valued functions defined on $S$ with supremum norm. For each $s \in S$, we define the left and right translation operators $l(s) f$ and $r(s) f$ on $B(S)$ by

$$
(l(s) f)(t)=f(s t), \quad \text { and } \quad(r(s) f)(t)=f(t s)
$$

for each $s \in S$ and $f \in B(S)$, respectively. Let $X$ be a subspace of $B(S)$ containing 1 and let $X^{*}$ be its topological dual. An element $\mu$ of $X^{*}$ is said to be a mean on $X$ if $\|\mu\|=\mu(1)=1$. Let $\mu \in X^{*}$. Then we define $r(s)^{*} \mu, l(s)^{*} \mu \in X^{*}$ by $\left(r(s)^{*} \mu\right) f=\mu(r(s) f),\left(l(s)^{*} \mu\right) f=\mu(l(s) f)$ for each $f \in X$ and $s \in S$. It is easy to see that if $\mu$ is a mean on $X$, then $r(s)^{*} \mu$ and $l(s)^{*} \mu$ are also. We often write $\mu_{t}(f(t))$ instead of $\mu(f)$ for $\mu \in X^{*}$ and $f \in X$. Let $X$ be left invariant (resp. right invariant), i.e., $l(s)(X) \subset X$ (resp. $r(s)(X) \subset X)$ for each $s \in S$. A mean $\mu$ on $X$ is said to be left invariant (resp. right invariant) if $l(s)^{*} \mu=\mu$ (resp. $\left.r(s)^{*} \mu=\mu\right)$ for each $s \in S$ and $f \in X . X$ is said to be left (resp. right) amenable if $X$ has a left (resp. right) invariant mean. The semigroup $S$ is amenable (i.e., $S$ is both left and right amenable) when $S$ is a commutative semigroup or a solvable group. However, the free group (or semigroup) on two generators is not left amenable. If a semigroup $S$ is left amenable, then $S$ is left 
reversible, but the converse is not true see [17], [18, p.335]. A net $\left\{\mu_{\alpha}\right\}$ of means on $X$ is said to be strongly left regular if

$$
\lim _{\alpha}\left\|l(s)^{*} \mu_{\alpha}-\mu_{\alpha}\right\|=0
$$

for each $s \in S$, where $l(s)^{*}$ is the adjoint operator of $l_{s}$.

Let $\varphi=\{T(s): s \in S\}$ be a representation of $S$ as a Lipschitzian mapping on $C$ with Lipschitz constant $\{l(s): s \in S\}$. By Fix $(\varphi)$ we denote the set of common fixed points of $\varphi$, i.e.,

$$
\operatorname{Fix}(\varphi)=\bigcap_{s \in S}\{x \in C: T(s) x=x\} .
$$

We denote by $C_{a}$ the set of almost periodic elements in $C$, i.e., all $x \in C$ such that $\{T(s) x$ : $s \in S\}$ is relatively compact in the norm topology of $E$. Let $X$ be a subspace of $B(S)$ such that the functions (i) $s \rightarrow\left\langle T(s) x, x^{*}\right\rangle$ and (ii) $s \rightarrow\|T(s) x-y\|$ on $S$ are in $X$ for all $x, y \in C$ and $x^{*} \in E^{*}$. We will call a subspace $X$ of $B(S)$ satisfying (i) and (ii) $\varphi$-stable. We know that if $X$ is a subspace of $B(S)$ containing 1 and the function $s \rightarrow\left\langle T(s) x, x^{*}\right\rangle$ on $S$ is in $X$ for all $x \in C$ and $x^{*} \in E^{*}$, then there exists a unique point $x_{0} \in E$ such that $\mu\left\langle T(\cdot) x, x^{*}\right\rangle=\left\langle x_{0}, x^{*}\right\rangle$ for a mean $\mu$ on $X, x \in C$ and $x^{*} \in E$. We denote such a point $x_{0} \in E$ by $T_{\mu} x$. See [19] for more details.

Lemma 2.1 [20] Let $S$ be a semigroup and $C$ be a nonempty closed convex subset of a reflexive Banach space E. Let $\varphi=\left\{T_{t}: t \in S\right\}$ be a nonexpansive semigroup on $H$ such that $\left\{T_{t} x: t \in S\right\}$ is bounded for some $x \in C$, let $X$ be a subspace of $B(S)$ such that $1 \in X$ and the mapping $t \rightarrow\left\langle T_{t} x, y^{*}\right\rangle$ is an element of $X$ for each $x \in C$ and $y^{*} \in E^{*}$, and $\mu$ is a mean on $X$. If we write $T_{\mu} x$ instead of $\int T_{t} x d \mu(t)$, then the following hold:

(i) $T_{\mu}$ is a nonexpansive mapping from $C$ into $C$.

(ii) $T_{\mu} x=x$ for each $x \in \operatorname{Fix}(\varphi)$.

(iii) $T_{\mu} x \in \overline{c o}\left\{T_{t} x: t \in S\right\}$ for each $x \in C$.

Lemma 2.2 [21] Let $\varphi=\{T(s): s \in S\}$ be a representation of $S$ as a Lipschitzian mapping from a nonempty weakly compact convex subset $C$ of a Banach space E into $C$, with uniform Lipschitzian constant $\lim _{s} l(s) \leq 1$ on the Lipschitz constant of mappings. Let $X$ be a left invariant and $\varphi$-stable subspace of $B(S)$, and let $\left\{\mu_{n}\right\}_{n=1}^{\infty}$ be an asymptotically left invariant sequence of means on $X$. If $z \in C_{a}$ and $\liminf _{n \rightarrow \infty}\left\|T_{\mu_{n}} z-z\right\|=0$, then $z$ is a common fixed point of $\varphi$.

Lemma 2.3 [2] Let $\varphi=\{T(s): s \in S\}$ be a representation of $S$ as a Lipschitzian mapping from a nonempty weakly compact convex subset $C$ of a Banach space $E$ into $C$, with uniform Lipschitzian constant $\lim _{s} l(s) \leq 1$ on the Lipschitz constant of mappings. Let $X$ be a left invariant subspace of $B(S)$ containing 1 such that the mapping $s \rightarrow\left\langle T(s) x, x^{*}\right\rangle$ on $S$ is in $X$ for all $x \in C$ and $x^{*} \in E^{*}$, and $\left\{\mu_{n}\right\}_{n=1}^{\infty}$ is an asymptotically left invariant sequence of means on $X$. Then

$$
\limsup _{n \rightarrow \infty}\left(\sup _{x, y \in C}\left(\left\|T_{\mu_{n}} x-T_{\mu_{n}} y\right\|-\|x-y\|\right)\right) \leq 0 .
$$


Let $D$ be a subset of $B$, where $B$ is a subset of a Banach space $E$, and let $P$ be a retraction of $B$ onto $D$, that is, $P x=x$ for each $x \in D$. Then $P$ is said to be sunny [22] if for each $x \in B$ and $t \geq 0$ with $P x+t(x-P x) \in B, P(P x+t(x-P x))=P x$. A subset $D$ of $B$ is said to be a sunny nonexpansive retract of $B$ if there exists a sunny nonexpansive retraction $P$ of $B$ into $D$.

Lemma 2.4 [1] Let $\varphi=\{T(s): s \in S\}$ be a representation of $S$ as a Lipschitzian mapping from a nonempty compact convex subset $C$ of a smooth Banach space E into $C$, with uniform Lipschitzian constant $\lim _{s} l(s) \leq 1$ on the Lipschitz constant of mappings. Let $X$ be a left invariant and $\varphi$-stable subspace of $B(S)$ containing 1 and $\mu$ be a left invariant mean on $X$. Then $\operatorname{Fix}(\varphi)$ is a sunny nonexpansive retract of $C$, and the sunny nonexpansive retraction of $C$ onto $\operatorname{Fix}(\varphi)$ is unique.

Lemma 2.5 [16] Let $C$ be a nonempty convex subset of a smooth Banach space E, let D be a nonempty subset of $C$, and let $P: C \rightarrow D$ be a retraction. Then the following are equivalent:

(a) $P$ is sunny nonexpansive.

(b) $\langle x-P x, J(y-P x)\rangle \leq 0$ for all $x \in C$ and $y \in D$.

(c) $\langle x-y, J(P x-P y)\rangle \geq\|P x-P y\|^{2}$ for all $x, y \in C$.

Lemma 2.6 [3] Let $\left\{x_{n}\right\}_{n=1}^{\infty}$ and $\left\{y_{n}\right\}_{n=1}^{\infty}$ be bounded sequences in a Banach space $X$, and let $\left\{\alpha_{n}\right\}_{n=1}^{\infty}$ be a sequence in $[0,1]$ such that $0<\liminf _{n \rightarrow \infty} \alpha_{n} \leq \limsup _{n \rightarrow \infty} \alpha_{n}<1$. Suppose $x_{n+1}=\alpha_{n} x_{n}+\left(1-\alpha_{n}\right) y_{n}$ for all integers $n \geq 0$ and

$$
\limsup _{n \rightarrow \infty}\left(\left\|y_{n+1}-y_{n}\right\|-\left\|x_{n+1}-x_{n}\right\|\right) \leq 0
$$

Then $\lim _{n \rightarrow \infty}\left\|y_{n}-x_{n}\right\|=0$.

Lemma 2.7 [19] Let E be a real smooth Banach space and J be the duality mapping. Then

$$
\|x+y\|^{2} \leq\|x\|^{2}+2\langle y, J(x+y)\rangle, \quad \forall x, y \in E .
$$

Lemma 2.8 [23] Let $\left\{a_{n}\right\}_{n=1}^{\infty}$ be a sequence of nonnegative real numbers such that

$$
a_{n+1} \leq\left(1-b_{n}\right) a_{n}+b_{n} c_{n}, \quad n \geq 0,
$$

where $\left\{b_{n}\right\}_{n=1}^{\infty}$ and $\left\{c_{n}\right\}_{n=1}^{\infty}$ are sequences of real numbers satisfying the following conditions:

(i) $\left\{b_{n}\right\}_{n=1}^{\infty} \subset(0,1), \sum_{n=0}^{\infty} b_{n}=\infty$,

(ii) either $\limsup _{n \rightarrow \infty} c_{n} \leq 0$ or $\sum_{n=0}^{\infty}\left|b_{n} c_{n}\right|<\infty$.

Then $\lim _{n \rightarrow \infty} a_{n}=0$.

Lemma 2.9 [16] Let $(X, d)$ be a metric space. A subset $C$ of $X$ is compact if and only if every sequence in $C$ contains a convergent subsequence with limit in $C$.

\section{The main result}

In this section, we establish a strong convergence theorem for finding a common fixed point of an asymptotically nonexpansive semigroup in a smooth Banach space. 
Theorem 3.1 Let $\varphi=\{T(s): s \in S\}$ be a representation of S as a Lipschitzian mapping from a nonempty compact convex subset $C$ of a smooth Banach space $E$ into $C$, with uniform Lipschitzian constant $\lim _{s} l(s) \leq 1$ on the Lipschitz constant of mappings, such that $\operatorname{Fix}(\varphi) \neq \emptyset$, and let $f$ be a contraction of $C$ into itself with constant $\alpha \in(0,1)$. Let $X$ be a left invariant and $\varphi$-stable subspace of $B(S)$ containing 1 and the function $t \rightarrow\left\langle T_{t} x, y\right\rangle$ is an element of $X$ for each $x \in C$ and $y \in H$, and let $\left\{\mu_{i, n}\right\}_{i=1, n=1}^{m, \infty}$ be a finite family of left regular sequences of invariant means on $X$ such that for $i=1,2, \ldots, m, \lim _{n \rightarrow \infty}\left\|\mu_{i, n+1}-\mu_{i, n}\right\|=0$. Let $\left\{\alpha_{n}\right\}_{n=1}^{\infty}$, $\left\{\beta_{n}\right\}_{n=1}^{\infty}$ and $\left\{\gamma_{n}\right\}_{n=1}^{\infty}$ be sequences in $(0,1)$ satisfying conditions $\left(\mathrm{C}_{1}\right)-\left(\mathrm{C}_{4}\right)$, and let $\left\{\delta_{n}\right\}_{i=1, n=1}^{m, \infty}$ be a sequence in $(0,1)$ satisfying the condition

$\left(C_{5}^{\prime}\right) \lim _{n \rightarrow \infty} \delta_{i, n}=1, i=1,2, \ldots, m$.

If $\left\{x_{n}\right\}_{n=1}^{\infty}$ and $\left\{y_{i, n}\right\}_{i=1, n=1}^{m, \infty}$ are sequences generated by $x_{1} \in C$ and

$$
\begin{aligned}
& x_{n+1}=\alpha_{n} f\left(y_{1, n}\right)+\beta_{n} x_{n}+\gamma_{n} T_{\mu_{1, n}} y_{1, n}, \\
& y_{i, n}=\delta_{i, n} y_{i+1, n}+\left(I-\delta_{i, n}\right) T_{\mu_{i, n}} y_{i+1, n}, \quad i=1,2, \ldots, m, \\
& y_{m+1, n}=x_{n},
\end{aligned}
$$

then $\left\{x_{n}\right\}_{n=1}^{\infty}$ and $\left\{y_{i, n}\right\}_{i=1, n=1}^{m, \infty}$ converge strongly to $z \in \operatorname{Fix}(\varphi)$, which is the unique solution of the variational inequality

$$
\langle(f-I) z, J(y-z)| \leq 0, \quad \forall y \in \operatorname{Fix}(\varphi) .
$$

Equivalently, $z=P f(z)$, where $P$ denotes the unique sunny nonexpansive retraction of $C$ onto $\operatorname{Fix}(\varphi)$.

Proof From Lemma 2.1 and the definition of $\left\{y_{i, n}\right\}_{i=1, n=1}^{m, \infty}$, for every $z \in \operatorname{Fix}(\varphi)$, we have

$$
\begin{aligned}
\left\|y_{i, n}-z\right\| & =\left\|\delta_{i, n} y_{i+1, n}+\left(1-\delta_{i, n}\right) T_{\mu_{i, n}} y_{i+1, n}-z\right\| \\
& \leq \delta_{i, n}\left\|y_{i+1, n}-z\right\|+\left(1-\delta_{i, n}\right)\left\|T_{\mu_{i, n}} y_{i+1, n}-T_{\mu_{i, n}} z\right\| \\
& =\delta_{i, n}\left\|y_{i+1, n}-z\right\|+\left(1-\delta_{i, n}\right)\left\|y_{i+1, n}-z\right\| \\
& =\left\|y_{i+1, n}-z\right\| .
\end{aligned}
$$

Therefore, we have

$$
\left\|y_{1, n}-z\right\| \leq\left\|y_{2, n}-z\right\| \leq \cdots \leq\left\|y_{m, n}-z\right\| \leq\left\|x_{n}-z\right\| .
$$

We shall divide the proof into several steps.

Step 1. Let $\left\{t_{n}\right\}_{n=1}^{\infty}$ be a sequence in $C$. Then

$$
\lim _{n \rightarrow \infty}\left\|T_{\mu_{i, n+1}} t_{n}-T_{\mu_{i, n}} t_{n}\right\|=0, \quad i=1,2, \ldots, m .
$$

Proof of Step 1. This assertion is proved in [24, 25].

Step 2. $\lim _{n \rightarrow \infty}\left\|x_{n+1}-x_{n}\right\|=0$. 
Proof of Step 2. From the definition of $\left\{y_{i, n}\right\}_{i=1, n=1}^{m, \infty}$, we have

$$
\begin{aligned}
\| y_{i, n+1} & -y_{i, n} \| \\
= & \| \delta_{i, n+1} y_{i+1, n+1}+\left(1-\delta_{i, n+1}\right) T_{\mu_{i, n+1}} y_{i+1, n+1} \\
& \quad-\delta_{i, n} y_{i+1, n}-\left(1-\delta_{i, n}\right) T_{\mu_{i, n}} y_{i+1, n} \| \\
= & \| \delta_{i, n+1} y_{i+1, n+1}-\delta_{i, n+1} y_{i+1, n}+\delta_{i, n+1} y_{i+1, n} \\
& +\left(1-\delta_{i, n+1}\right) T_{\mu_{i, n+1}} y_{i+1, n+1}-\delta_{i, n} y_{i+1, n}-\left(1-\delta_{i, n}\right) T_{\mu_{i, n}} y_{i+1, n} \| \\
\leq & \delta_{i, n+1}\left\|y_{i+1, n+1}-y_{i+1, n}\right\|+\left|\delta_{i, n+1}-\delta_{i, n}\right|\left\|y_{i+1, n}\right\| \\
& +\left(1-\delta_{i, n+1}\right)\left\|T_{\mu_{i, n+1}} y_{i+1, n+1}\right\|+\left(1-\delta_{i, n}\right)\left\|T_{\mu_{i, n}} y_{i+1, n}\right\| \\
\leq & \left\|y_{i+1, n+1}-y_{i+1, n}\right\|+\left|\delta_{i, n+1}-\delta_{i+1, n}\right|\left\|y_{i+1, n}\right\| \\
& +\left(1-\delta_{i, n+1}\right)\left\|T_{\mu_{i, n+1}} y_{i+1, n+1}\right\|+\left(1-\delta_{i, n}\right)\left\|T_{\mu_{i, n}} y_{i+1, n}\right\|,
\end{aligned}
$$

which implies that

$$
\begin{aligned}
& \left\|y_{i, n+1}-y_{i, n}\right\| \\
& \quad \leq\left\|x_{n+1}-x_{n}\right\|+\sum_{j=i}^{m}\left(\left|\delta_{j, n+1}-\delta_{j, n}\right|\left\|y_{j+1, n}\right\|\right. \\
& \left.\quad+\left(1-\delta_{i, n+1}\right)\left\|T_{\mu_{i, n+1}} y_{i+1, n+1}\right\|+\left(1-\delta_{i, n}\right)\left\|T_{\mu_{i, n}} y_{i+1, n}\right\|\right) .
\end{aligned}
$$

Define

$$
x_{n+1}=\left(1-\beta_{n}\right) z_{n}+\beta_{n} x_{n}, \quad n \geq 1 \text {. }
$$

Observe that from the definition of $z_{n}$, we obtain

$$
\begin{aligned}
z_{n+1}-z_{n}= & \frac{x_{n+2}-\beta_{n+1} x_{n+1}}{1-\beta_{n+1}}-\frac{x_{n+1}-\beta_{n} x_{n}}{1-\beta_{n}} \\
= & \frac{\alpha_{n+1} f\left(y_{1, n+1}\right)+\gamma_{n+1} T_{\mu_{1, n+1}} y_{1, n+1}}{1-\beta_{n+1}}-\frac{\alpha_{n} f\left(y_{1, n}\right)+\gamma_{n} T_{\mu_{1, n}} y_{1, n}}{1-\beta_{n}} \\
= & \frac{\alpha_{n+1}}{1-\beta_{n+1}}\left(f\left(y_{1, n+1}\right)-T_{\mu_{1, n+1}} y_{1, n+1}\right)-\frac{\alpha_{n}}{1-\beta_{n}}\left(f\left(y_{1, n}\right)-T_{\mu_{1, n}} y_{1, n}\right) \\
& +T_{\mu_{1, n+1}} y_{1, n+1}-T_{\mu_{1, n}} y_{1, n} .
\end{aligned}
$$

It follows that

$$
\begin{aligned}
\| z_{n+1} & -z_{n} \| \\
\leq & \left.\frac{\alpha_{n+1}}{1-\beta_{n+1}} \| f\left(y_{1, n+1}\right)-T_{\mu_{1, n+1}} y_{1, n+1}\right) \| \\
& \quad+\frac{\alpha_{n}}{1-\beta_{n}}\left\|f\left(y_{1, n}\right)-T_{\mu_{1, n}} y_{1, n}\right\| \\
& \quad\left\|y_{1, n+1}-y_{1, n}\right\|+\left\|T_{\mu_{1, n+1}} y_{1, n}-T_{\mu_{1, n}} y_{1, n}\right\| .
\end{aligned}
$$


Substituting (8) into (10), we obtain

$$
\begin{aligned}
& \left\|z_{n+1}-z_{n}\right\|-\left\|x_{n+1}-x_{n}\right\| \\
& \leq \frac{\alpha_{n+1}}{1-\beta_{n+1}}\left\|f\left(y_{1, n+1}\right)-T_{\mu_{1, n+1}} y_{1, n+1}\right\| \\
& \quad+\frac{\alpha_{n}}{1-\beta_{n}}\left\|f\left(y_{1, n}\right)-T_{\mu_{1, n}} y_{1, n}\right\| \\
& \quad+\left\|T_{\mu_{1, n+1}} y_{1, n}-T_{\mu_{1, n}} y_{1, n}\right\|+\sum_{j=1}^{m}\left(\left|\delta_{j, n+1}-\delta_{j, n}\right|\left\|y_{j+1, n}\right\|\right. \\
& \left.\quad+\left(1-\delta_{i, n+1}\right)\left\|T_{\mu_{i, n+1}} y_{i+1, n+1}\right\|+\left(1-\delta_{i, n}\right)\left\|T_{\mu_{i, n}} y_{i+1, n}\right\|\right) .
\end{aligned}
$$

It follows from Step 1 , conditions $\left(C_{2}\right)$ and $\left(C_{5}^{\prime}\right)$ that

$$
\limsup _{n \rightarrow \infty}\left(\left\|z_{n+1}-z_{n}\right\|-\left\|x_{n+1}-x_{n}\right\|\right) \leq 0
$$

Applying Lemma 2.6 to (9), we get

$$
\lim _{n \rightarrow \infty}\left\|x_{n}-z_{n}\right\|=0
$$

\section{Consequently,}

$$
\lim _{n \rightarrow \infty}\left\|x_{n+1}-x_{n}\right\|=\lim _{n \rightarrow \infty}\left(1-\beta_{n}\right)\left\|x_{n}-z_{n}\right\|=0 .
$$

Step 3. We claim that $\omega\left(\left\{x_{n}\right\}_{n=1}^{\infty}\right) \subset \operatorname{Fix}(\varphi)$, where

$$
\omega\left(\left\{x_{n}\right\}_{n=1}^{\infty}\right):=\left\{x \in C:\left\{x_{n_{j}}\right\}_{j=1}^{\infty} \subset\left\{x_{n}\right\}_{n=1}^{\infty}, \lim _{j \rightarrow \infty}\left\|x_{n_{j}}-x\right\|=0\right\} .
$$

Proof of Step 3. From Lemma 2.9, we get $\omega\left(\left\{x_{n}\right\}_{n=1}^{\infty}\right) \neq \emptyset$.

Let $x \in \omega\left(\left\{x_{n}\right\}_{n=1}^{\infty}\right)$. Then there exists a subsequence $\left\{x_{n_{j}}\right\}_{j=1}^{\infty}$ of $\left\{x_{n}\right\}_{n=1}^{\infty}$ such that

$$
\lim _{j \rightarrow \infty}\left\|x_{n_{j}}-x\right\|=0
$$

Observe that

$$
\begin{aligned}
\| x_{n}- & T_{\mu_{1, n}} x_{n} \| \\
\leq & \left\|x_{n}-x_{n+1}\right\|+\left\|x_{n+1}-T_{\mu_{1, n}} x_{n}\right\| \\
= & \left\|x_{n}-x_{n+1}\right\|+\| \alpha_{n}\left(f\left(y_{1, n}\right)-T_{\mu_{1, n}} x_{n}\right)+\beta_{n}\left(x_{n}-T_{\mu_{1, n}} x_{n}\right) \\
& +\gamma_{n}\left(T_{\mu_{1, n}} y_{1, n}-T_{\mu_{1, n}} x_{n}\right) \| \\
\leq & \left\|x_{n}-x_{n+1}\right\|+\alpha_{n}\left\|f\left(y_{1, n}\right)-T_{\mu_{1, n}} x_{n}\right\|+\beta_{n}\left\|x_{n}-T_{\mu_{1, n}} x_{n}\right\| \\
& +\gamma_{n}\left\|T_{\mu_{1, n}} y_{1, n}-T_{\mu_{1, n}} x_{n}\right\| \\
\leq & \left\|x_{n}-x_{n+1}\right\|+\alpha_{n}\left\|f\left(y_{1, n}\right)-T_{\mu_{1, n}} x_{n}\right\|+\beta_{n}\left\|x_{n}-T_{\mu_{1, n}} x_{n}\right\| \\
& +\gamma_{n}\left\|y_{1, n}-x_{n}\right\|
\end{aligned}
$$




$$
\begin{aligned}
\leq & \left\|x_{n}-x_{n+1}\right\|+\alpha_{n}\left\|f\left(y_{1, n}\right)-T_{\mu_{1, n}} x_{n}\right\|+\beta_{n}\left\|x_{n}-T_{\mu_{1, n}} x_{n}\right\| \\
& +\gamma_{n} \sum_{i=1}^{m}\left\|y_{i, n}-y_{i+1, n}\right\| \\
= & \left\|x_{n}-x_{n+1}\right\|+\alpha_{n}\left\|f\left(y_{1, n}\right)-T_{\mu_{1, n}} x_{n}\right\|+\beta_{n}\left\|x_{n}-T_{\mu_{1, n}} x_{n}\right\| \\
& +\gamma_{n} \sum_{i=1}^{m}\left(1-\delta_{i, n}\right)\left\|y_{i+1, n}-T_{\mu_{i, n}} y_{i+1, n}\right\| .
\end{aligned}
$$

Therefore, we have

$$
\begin{aligned}
& \left(1-\beta_{n}\right)\left\|x_{n}-T_{\mu_{1, n}} x_{n}\right\| \\
& \leq\left\|x_{n}-x_{n+1}\right\|+\alpha_{n}\left\|f\left(y_{1, n}\right)-T_{\mu_{1, n}} x_{n}\right\| \\
& \quad+\gamma_{n} \sum_{i=1}^{m}\left(1-\delta_{i, n}\right)\left\|y_{i+1, n}-T_{\mu_{i, n}} y_{i+1, n}\right\| .
\end{aligned}
$$

From condition $\left(\mathrm{C}_{4}\right)$, it follows that

$$
\liminf _{n \rightarrow \infty}\left(1-\beta_{n}\right)>0
$$

By conditions $\left(C_{2}\right)$ and $\left(C_{5}^{\prime}\right)$, Step $2,(13)$ and (14), we have

$$
\lim _{n \rightarrow \infty}\left\|x_{n}-T_{\mu_{1, n}} x_{n}\right\|=0
$$

Indeed, observe that

$$
\begin{gathered}
\limsup _{j \rightarrow \infty}\left\|x-T_{\mu_{1, n_{j}}} x\right\| \leq \limsup _{j \rightarrow \infty}\left(\left\|x-x_{n_{j}}\right\|+\left\|x_{n_{j}}-T_{\mu_{1, n_{j}}} x_{n_{j}}\right\|\right. \\
\left.+\left\|T_{\mu_{1, n_{j}}} x_{n_{j}}-T_{\mu_{1, n_{j}}} x\right\|\right) .
\end{gathered}
$$

Thus, due to (15), Lemma 2.2 and Lemma 2.3, we get $x \in \operatorname{Fix}(\varphi)$.

Step 4. $\left\{x_{n}\right\}_{n=1}^{\infty}$ converges strongly to $z=P f(z)$.

Proof of Step 4. From Lemma 2.4 there exists a unique sunny nonexpansive retraction $P$ of $C$ onto $\operatorname{Fix}(\varphi)$. Since $f$ is a contraction of $C$ into itself, therefore $P f$ is a contraction. Then the Banach contraction guarantees that $P f$ has a unique fixed point $z$. By Lemma 2.5, $z$ is the unique solution of the variational inequality

$$
\langle(f-I) z, J(y-z)\rangle \leq 0, \quad \forall y \in \operatorname{Fix}(\varphi)
$$

Let us show that

$$
\limsup _{n \rightarrow \infty}\left\langle(f-I) z, J\left(x_{n}-z\right)\right\rangle \leq 0 .
$$

Indeed, we can choose a subsequence $\left\{x_{n_{k}}\right\}$ of $\left\{x_{n}\right\}$ such that

$$
\limsup _{n \rightarrow \infty}\left\langle(f-I) z, J\left(x_{n}-z\right)\right\rangle=\lim _{k \rightarrow \infty}\left\langle(f-I) z, J\left(x_{n_{k}}-z\right)\right\rangle .
$$


Since $C$ is compact, we may assume, with no loss of generality, that $\left\{x_{n_{k}}\right\}$ converges strongly to some $y \in C$. By Step 3, $y \in \operatorname{Fix}(\varphi)$. Because the duality mapping $J$ is norm to weak-star continuous from (16) and (17), we have

$$
\limsup _{n \rightarrow \infty}\left\langle(f-I) z, J\left(x_{n}-z\right)\right\rangle \leq 0 .
$$

Using Lemma 2.1, Lemma 2.7 and relation (7), we have

$$
\begin{aligned}
&\left\|x_{n+1}-z\right\|^{2} \\
&=\left\|\alpha_{n}\left(f\left(y_{1, n}\right)-z\right)+\beta_{n}\left(x_{n}-z\right)+\gamma_{n}\left(T_{\mu_{1, n}} y_{1, n}-z\right)\right\|^{2} \\
& \leq\left\|\beta_{n}\left(x_{n}-z\right)+\gamma_{n}\left(T_{\mu_{1, n}} y_{1, n}-z\right)\right\|^{2}+2 \alpha_{n}\left\langle f\left(y_{1, n}\right)-z, J\left(x_{n+1}-z\right)\right\rangle \\
& \leq {\left[\beta_{n}\left\|x_{n}-z\right\|+\gamma_{n}\left\|T_{\mu_{1, n}} y_{1, n}-z\right\|\right]^{2}+2 \alpha_{n}\left\langle f\left(y_{1, n}\right)-f(z), J\left(x_{n+1}-z\right)\right\rangle } \\
&+2 \alpha_{n}\left\langle f(z)-z, J\left(x_{n+1}-z\right)\right\rangle \\
& \leq {\left[\beta_{n}\left\|x_{n}-z\right\|+\gamma_{n}\left\|y_{1, n}-z\right\|\right]^{2}+2 \alpha_{n} \alpha\left\|y_{1, n}-z\right\|\left\|J\left(x_{n+1}-z\right)\right\| } \\
&+2 \alpha_{n}\left\langle f(z)-z, J\left(x_{n+1}-z\right)\right\rangle \\
& \leq {\left[\beta_{n}\left\|x_{n}-z\right\|+\gamma_{n}\left\|x_{n}-z\right\|\right]^{2}+2 \alpha_{n} \alpha\left\|x_{n}-z\right\|\left\|x_{n+1}-z\right\| } \\
&+2 \alpha_{n}\left\langle f(z)-z, J\left(x_{n+1}-z\right)\right\rangle \\
& \leq\left(1-\alpha_{n}\right)^{2}\left\|x_{n}-z\right\|^{2}+\alpha_{n} \alpha\left(\left\|x_{n}-z\right\|^{2}+\left\|x_{n+1}-z\right\|^{2}\right) \\
&+2 \alpha_{n}\left\langle f(z)-z, J\left(x_{n+1}-z\right)\right\rangle,
\end{aligned}
$$

and consequently,

$$
\begin{aligned}
\left\|x_{n+1}-z\right\|^{2} & \\
\leq & \frac{\left(1-\alpha_{n}\right)^{2}+\alpha_{n} \alpha}{1-\alpha_{n} \alpha}\left\|x_{n}-z\right\|^{2}+\frac{2 \alpha_{n}}{1-\alpha_{n} \alpha}\left\langle f(z)-z, J\left(x_{n+1}-z\right)\right\rangle \\
\leq & \left(1-\frac{2 \alpha_{n}\left(1-\alpha_{n}\right)}{1-\alpha_{n} \alpha}\right)\left\|x_{n}-z\right\|^{2} \\
& +\frac{2 \alpha_{n}\left(1-\alpha_{n}\right)}{1-\alpha_{n} \alpha}\left(\frac{1}{1-\alpha}\left\langle f(z)-z, J\left(x_{n+1}-z\right)\right\rangle+\frac{\alpha_{n}}{2(1-\alpha)}\left\|x_{n}-z\right\|^{2}\right) .
\end{aligned}
$$

Then we have

$$
\left\|x_{n+1}-z\right\|^{2} \leq\left(1-b_{n}\right)\left\|x_{n}-z\right\|^{2}+b_{n} c_{n}
$$

where $b_{n}=\frac{2 \alpha_{n}\left(1-\alpha_{n}\right)}{1-\alpha_{n} \alpha}$ and

$$
c_{n}=\frac{1}{1-\alpha}\left\langle f(z)-z, J\left(x_{n+1}-z\right)\right\rangle+\frac{\alpha_{n}}{2(1-\alpha)}\left\|x_{n}-z\right\|^{2} .
$$

It follows from conditions $\left(\mathrm{C}_{2}\right),\left(\mathrm{C}_{3}\right)$ and $(18)$ that

$$
\sum_{n=1}^{\infty} b_{n}=\infty, \quad \limsup _{n \rightarrow \infty} c_{n} \leq 0
$$


Therefore, applying Lemma 2.8 to (19), we have that $\left\{x_{n}\right\}_{n=1}^{\infty}$ converges strongly to $z=P f(z)$ and since for $i=1,2, \ldots, m,\left\|y_{i, n}-z\right\| \leq\left\|x_{n}-z\right\|$, therefore $\left\{y_{n}\right\}_{i=1, n=1}^{m, \infty}$ converges strongly to $z=P f(z)$. This completes the proof.

\section{Applications}

Let $\left\{g_{n, j}\right\}_{n, j=0}^{\infty}$ be a family of real numbers. Then $\left\{g_{n, j}\right\}$ is said to be the strongly regular summation method $[26,27]$ if $\left\{g_{n, j}\right\}$ satisfies the following conditions:

$\left(\mathrm{S}_{1}\right) g_{n, j} \geq 0$

$\left(\mathrm{S}_{2}\right) \sum_{j=0}^{\infty} g_{n, j}=1$ for every $n$,

$\left(\mathrm{S}_{3}\right) \lim _{n \rightarrow \infty} g_{n, j}=0$ for every $j$,

$\left(\mathrm{S}_{4}\right) \lim _{n \rightarrow \infty} \sum_{j=0}^{\infty}\left|g_{n, j+1}-g_{n, j}\right|=0$.

Corollary 4.1 Let $C$ be a compact convex subset of a smooth Banach space E, and let $f$ be a contraction of $C$ into itself with constant $\alpha \in(0,1)$. Let $T$ be an asymptotically nonexpansive mapping of $C$ into itself with Lipschitz constants $\{k(j)\}$, and for $i=1,2, \ldots, m$, let $\left\{g_{(i, n), j}\right\}_{n, j=0}^{\infty}$ be a finite family of strongly regular summation methods such that

$$
\lim _{n \rightarrow \infty} \sum_{j=0}^{\infty}\left|g_{(i, n), j+1}-g_{(i, n), j}\right|=0 \quad \text { and } \quad \sum_{n=0}^{\infty} \sum_{j=0}^{\infty} g_{(i, n), j}(k(j)-1)<\infty
$$

Let $\left\{\alpha_{n}\right\}_{n=1}^{\infty},\left\{\beta_{n}\right\}_{n=1}^{\infty}$ and $\left\{\gamma_{n}\right\}_{n=1}^{\infty}$ be sequences in $(0,1)$ satisfying conditions $\left(\mathrm{C}_{1}\right)-\left(\mathrm{C}_{4}\right)$, and let $\left\{\delta_{i, n}\right\}_{i=1, n=1}^{m, \infty}$ be a sequence in $(0,1)$ satisfying condition $\left(\mathrm{C}_{5}^{\prime}\right)$. If $\left\{x_{n}\right\}_{n=1}^{\infty}$ and $\left\{y_{i, n}\right\}_{i=1, n=1}^{m, \infty}$ are sequences generated by $x_{1} \in C$ and

$$
\begin{aligned}
& x_{n+1}=\alpha_{n} f\left(y_{1, n}\right)+\beta_{n} x_{n}+\gamma_{n} \sum_{j=0}^{\infty} g_{(1, n), j} T(j) y_{1, n}, \\
& y_{i, n}=\delta_{i, n} y_{i+1, n}+\left(I-\delta_{i, n}\right) \sum_{j=0}^{\infty} g_{(i, n), j} T(j) y_{i+1, n}, \quad i=1,2, \ldots, m, \\
& y_{m+1, n}=x_{n},
\end{aligned}
$$

then $\left\{x_{n}\right\}_{n=1}^{\infty}$ and $\left\{y_{i, n}\right\}_{i=1, n=1}^{m, \infty}$ converge strongly to $z \in \operatorname{Fix}(T)$, which is the unique solution of the variational inequality

$$
\langle(f-I) z, J(y-z)\rangle \leq 0, \quad \forall y \in \operatorname{Fix}(T) .
$$

Equivalently, $z=P f(z)$, where $P$ denotes the unique sunny nonexpansive retraction of $C$ onto $\operatorname{Fix}(T)$.

Proof Denote by $\mathbb{Z}_{+}=(\mathbb{Z},+)$ the semigroup of nonnegative integers. It is obvious that $\varphi=$ $\left\{T^{j}: j \in \mathbb{Z}\right\}$ is an asymptotically nonexpansive semigroup on $C$. For every $n \in \mathbb{Z}_{+}$and $f \in$ $l^{\infty}\left(\mathbb{Z}_{+}\right)$, define

$$
\mu_{i, n} f=\sum_{j=0}^{\infty} g_{(i, n), j} f(j)
$$


Hence $\left\{\mu_{i, n}\right\}_{i=1, n=1}^{m, \infty}$ is a strongly regular sequence of means on $l^{\infty}\left(\mathbb{Z}_{+}\right)$and $\lim _{n \rightarrow \infty} \| \mu_{i, n+1}-$ $\mu_{i, n} \|=0$ [28]. Further, for each $y \in C$, we have

$$
T_{\mu_{i, n}}=\sum_{j=0}^{\infty} g_{(i, n), j} T(j) y .
$$

By Theorem 3.1, $\left\{x_{n}\right\}_{n=1}^{\infty}$ and $\left\{y_{i, n}\right\}_{i=1, n=1}^{m, \infty}$ converge strongly to $z \in \operatorname{Fix}(T)$. This completes the proof.

Example 4.2 Let $C$ be a compact convex subset of a smooth Banach space $E$ such that $0 \in C$, and let $f$ be a contraction of $C$ into itself with constant $\alpha \in(0,1)$. Let $\left\{\alpha_{n}\right\}_{n=1}^{\infty},\left\{\beta_{n}\right\}_{n=1}^{\infty}$ and $\left\{\gamma_{n}\right\}_{n=1}^{\infty}$ be sequences in $(0,1)$ satisfying conditions $\left(C_{1}\right)-\left(C_{4}\right)$, and let $\left\{\delta_{n}\right\}_{n=1}^{\infty}$ be a sequence in $(0,1)$ satisfying condition $\left(C_{5}^{\prime}\right)$. Let $\left\{t_{n}\right\}_{n=1}^{\infty}$ be sequences in $(0,1)$ with $t_{1}>t_{2}>\cdots$, $\lim _{n \rightarrow \infty} t_{n}=0, \lim _{n \rightarrow \infty} \frac{t_{n+1}}{t_{n}}=1$ and $\sum_{n=0}^{\infty} t_{n}<\infty$. Let $\left\{x_{n}\right\}_{n=1}^{\infty}$ and $\left\{y_{n}\right\}_{n=1}^{\infty}$ be sequences generated by $x_{1} \in C$ and

$$
\begin{aligned}
& x_{n+1}=\alpha_{n} f\left(y_{n}\right)+\beta_{n} x_{n}+\gamma_{n} t_{n} \sum_{j=0}^{\infty}\left(1-t_{n}\right)^{j} \sqrt[n]{\left(1+\frac{1}{n^{2}}\right)^{j}} y_{n}, \\
& y_{n}=\delta_{n} x_{n}+\left(I-\delta_{n}\right) t_{n} \sum_{j=0}^{\infty}\left(1-t_{n}\right)^{j} \sqrt[n]{\left(1+\frac{1}{n^{2}}\right)^{j} x_{n} .}
\end{aligned}
$$

Then $\left\{x_{n}\right\}_{n=1}^{\infty}$ and $\left\{y_{n}\right\}_{n=1}^{\infty}$ converge strongly to $z \in C$.

Proof We define

$$
\begin{aligned}
& T: C \rightarrow C, \\
& T x=\sqrt[n]{\left(1+\frac{1}{n^{2}}\right) x .}
\end{aligned}
$$

Obviously, $T$ is an asymptotically nonexpansive mapping with Lipschitz constants $l_{n}=$ $\left(1+\frac{1}{n^{2}}\right)$. Define $g_{n, j}=t_{n}\left(1-t_{n}\right)^{j}$. Then it follows that $\left\{q_{n, j}\right\}$ is a strongly regular summation method [28]. We also have

$$
\begin{aligned}
\sum_{n=0}^{\infty} \sum_{j=0}^{\infty} g_{n, j}\left(l_{n}-1\right) & =\sum_{n=0}^{\infty} \sum_{j=0}^{\infty} t_{n}\left(1-t_{n}\right)^{j}\left(1+\frac{1}{n^{2}}-1\right) \\
& =\sum_{n=0}^{\infty} \sum_{j=0}^{\infty} t_{n}\left(1-t_{n}\right)^{j} \frac{1}{n^{2}} \\
& \leq \sum_{n=0}^{\infty} \sum_{j=0}^{\infty} t_{n} \frac{1}{n^{2}} \\
& =\sum_{n=0}^{\infty} t_{n} \sum_{j=0}^{\infty} \frac{1}{n^{2}}<\infty .
\end{aligned}
$$

Therefore, by taking $y_{1, n}=y_{n}$ and $\delta_{1, n}=\delta_{n}$ in Corollary 4.1, we complete the proof. 
Let $Q=\left\{q_{n, m}\right\}_{n, m=0}^{\infty}$ be a matrix satisfying the following conditions:

(a) $\sup _{n \geq 0} \sum_{m=0}^{\infty}\left|q_{n, m}\right|<\infty$,

(b) $\sum_{m=0}^{\infty} q_{n, m}=1$ for every $n \in \mathbb{N}$,

(c) $\lim _{n \rightarrow \infty} \sum_{m=0}^{\infty}\left|q_{n, m+1}-q_{n, m}\right|=0$.

Such a matrix $Q$ is called strongly regular in the sense of Lorentz [29]. If $Q$ is a strongly regular matrix, then for each $m \in \mathbb{N}$, we have $\lim _{n \rightarrow \infty} q_{n, m}=0$, see [30]. Strongly regular matrices were used in the context of nonlinear ergodic theory in [31] and [32].

Corollary 4.3 Let C be a compact convex subset of a smooth Banach space E. Let $T$ be an asymptotically nonexpansive mapping of $C$ into itself, and let $Q=\left\{q_{n, m}\right\}_{n, m=0}^{\infty}$ be a strongly regular matrix. Let $\left\{\alpha_{n}\right\}_{n=1}^{\infty},\left\{\beta_{n}\right\}_{n=1}^{\infty}$ and $\left\{\gamma_{n}\right\}_{n=1}^{\infty}$ be sequences in $(0,1)$ satisfying conditions $\left(\mathrm{C}_{1}\right)-\left(\mathrm{C}_{4}\right)$, and let $\left\{\delta_{n}\right\}_{i=1, n=1}^{m, \infty}$ be a sequence in $(0,1)$ satisfying condition $\left(\mathrm{C}_{5}^{\prime}\right)$. If $\left\{x_{n}\right\}_{n=1}^{\infty}$ and $\left\{y_{i, n}\right\}_{i=1, n=1}^{m, \infty}$ are sequences generated by $x_{1} \in C$ and

$$
\begin{aligned}
& x_{n+1}=\alpha_{n} f\left(y_{1, n}\right)+\beta_{n} x_{n}+\gamma_{n} \sum_{m=0}^{\infty} q_{(1, n), m} T^{m} y_{1, n}, \\
& y_{i, n}=\delta_{i, n} y_{i+1, n}+\left(I-\delta_{i, n}\right) \sum_{m=0}^{\infty} q_{(i, n), m} T^{m} y_{i+1, n}, \quad i=1,2, \ldots, m, \\
& y_{m+1, n}=x_{n},
\end{aligned}
$$

then $\left\{x_{n}\right\}_{n=1}^{\infty}$ and $\left\{y_{i, n}\right\}_{i=1, n=1}^{m, \infty}$ converge strongly to $z \in \operatorname{Fix}(T)$, which is the unique solution of the variational inequality

$$
\langle(f-I) z, J(y-z)\rangle \leq 0, \quad \forall y \in \operatorname{Fix}(T) .
$$

Equivalently, $z=\operatorname{Pf}(z)$, where $P$ denotes the unique sunny nonexpansive retraction of $C$ onto $\operatorname{Fix}(T)$.

Proof Let $x \in C$. For each $n \in \mathbb{N}$, define

$$
\mu_{i, n} f=\sum_{m=0}^{\infty} q_{(i, n), m} f(m)
$$

for each $f \in L^{\infty}(\mathbb{N})$. Hence $\left\{\mu_{i, n}\right\}_{i=1, n=1}^{m, \infty}$ is a strongly regular sequence of means on $l^{\infty}\left(\mathbb{Z}_{+}\right)$ and $\lim _{n \rightarrow \infty}\left\|\mu_{i, n+1}-\mu_{i, n}\right\|=0$ [33]. Further, for each $y \in C$, we have

$$
T_{\mu_{i, n}}=\sum_{m=0}^{\infty} q_{(i, n), m} T^{m} y .
$$

By Theorem 3.1, $\left\{x_{n}\right\}_{n=1}^{\infty}$ and $\left\{y_{i, n}\right\}_{i=1, n=1}^{m, \infty}$ converge strongly to $z \in \operatorname{Fix}(T)$. This completes the proof.

Example 4.4 Let $C$ be a compact convex subset of a smooth Banach space $E$ such that $0 \in C$, and let $f$ be a contraction of $C$ into itself with constant $\alpha \in(0,1)$. Let $\left\{\alpha_{n}\right\}_{n=1}^{\infty},\left\{\beta_{n}\right\}_{n=1}^{\infty}$ 
and $\left\{\gamma_{n}\right\}_{n=1}^{\infty}$ be sequences in $(0,1)$ satisfying conditions $\left(C_{1}\right)-\left(C_{4}\right)$, and let $\left\{\delta_{n}\right\}_{n=1}^{\infty}$ be a sequence in $(0,1)$ satisfying condition $\left(C_{5}^{\prime}\right)$. Let $\left\{x_{n}\right\}_{n=1}^{\infty}$ and $\left\{y_{n}\right\}_{n=1}^{\infty}$ be sequences generated by $x_{1} \in C$ and

$$
\begin{aligned}
& x_{n+1}=\alpha_{n} f\left(y_{n}\right)+\beta_{n} x_{n}+\gamma_{n} \sum_{m=0}^{n} \frac{2 m}{n(n-1)} \sqrt[n]{\left(1-\frac{1}{n^{2}}\right)^{m}} y_{n}, \\
& y_{n}=\delta_{n} x_{n}+\left(I-\delta_{n}\right) \sum_{m=0}^{n} \frac{2 m}{n(n-1)} \sqrt[n]{\left(1-\frac{1}{n^{2}}\right)^{m} x_{n} .}
\end{aligned}
$$

Then $\left\{x_{n}\right\}_{n=1}^{\infty}$ and $\left\{y_{n}\right\}_{n=1}^{\infty}$ converge strongly to $z \in C$.

Proof We define

$$
\begin{aligned}
& T: C \rightarrow C, \\
& T x=\sqrt[n]{\left(1-\frac{1}{n^{2}}\right) x .}
\end{aligned}
$$

Obviously, $T$ is an asymptotically nonexpansive mapping with Lipschitz constants $l_{n}=$ $\left(1-\frac{1}{n^{2}}\right)$. Define

$$
q_{n, m}= \begin{cases}\frac{2 m}{n(n-1)}, & 0 \leq m \leq n \\ 0, & m>n\end{cases}
$$

Then it follows that $\left\{q_{n, m}\right\}$ is a strongly regular matrix. Further, we have

$$
\sum_{m=0}^{\infty} q_{n, m}=\sum_{m=0}^{n} \frac{2 m}{n(n-1)}=\frac{2}{n(n-1)} \frac{n(n-1)}{2}=1
$$

Therefore

$$
\sup _{n \geq 0} \sum_{m=0}^{\infty} q_{n, m}<\infty
$$

On the other hand,

$$
\begin{aligned}
\sum_{m=0}^{\infty}\left|q_{n, m+1}-q_{n, m}\right| & =\sum_{m=0}^{n}\left|q_{n, m+1}-q_{n, m}\right| \\
& =\sum_{m=0}^{n-1}\left|q_{n, m+1}-q_{n, m}\right|+\left|q_{n, n+1}-q_{n, n}\right| \\
& =\sum_{m=0}^{n-1}\left|\frac{2(m+1)}{n(n-1)}-\frac{2 m}{n(n-1)}\right|+\left|0-\frac{2 n}{n(n-1)}\right| \\
& =\sum_{m=0}^{n-1}\left|\frac{2(m+1)}{n(n-1)}-\frac{2 m}{n(n-1)}\right|+\frac{2 n}{n(n-1)}
\end{aligned}
$$




$$
\begin{aligned}
& =\sum_{m=0}^{n-1} \frac{2}{n(n-1)}+\frac{2 n}{n(n-1)} \\
& =\frac{4 n}{n(n-1)} \rightarrow 0
\end{aligned}
$$

as $n \rightarrow \infty$. By taking $y_{1, n}=y_{n}$ and $\delta_{1, n}=\delta_{n}$ in Corollary 4.3, we complete the proof.

Corollary 4.5 Let $C$ be a compact convex subset of a smooth Banach space E such that $0 \in C$, and let $T$ be an asymptotically nonexpansive mapping of $C$ into itself with Lipschitz constants $\{k(j)\}$ satisfying $\sum_{j=0}^{\infty}(k(j)-1)<\infty$. Let $f$ be a contraction of $C$ into itself with constant $\alpha \in(0,1)$, let $\left\{\alpha_{n}\right\}_{n=1}^{\infty},\left\{\beta_{n}\right\}_{n=1}^{\infty}$ and $\left\{\gamma_{n}\right\}_{n=1}^{\infty}$ be sequences in $(0,1)$ satisfying conditions $\left(\mathrm{C}_{1}\right)-\left(\mathrm{C}_{4}\right)$, and let $\left\{\delta_{n}\right\}_{n=1}^{\infty}$ be a sequence in $(0,1)$ satisfying condition $\left(\mathrm{C}_{5}^{\prime}\right)$. If $\left\{x_{n}\right\}_{n=1}^{\infty}$ and $\left\{y_{n}\right\}_{n=1}^{\infty}$ are sequences generated by $x_{1} \in C$ and

$$
\begin{aligned}
& y_{n}=\delta_{n} x_{n}+\frac{2\left(1-\delta_{n}\right)}{(n+1)^{2}} \sum_{j=0}^{(n+1)^{2}} T^{j} x_{n}, \\
& x_{n+1}=\alpha_{n} f\left(y_{n}\right)+\beta_{n} x_{n}+\frac{2 \gamma_{n}}{(n+1)^{2}} \sum_{j=0}^{(n+1)^{2}} T^{j} y_{n},
\end{aligned}
$$

then $\left\{x_{n}\right\}_{n=1}^{\infty}$ and $\left\{y_{n}\right\}_{n=1}^{\infty}$ converge strongly to $z \in \operatorname{Fix}(T)$, which is the unique solution of the variational inequality

$$
\langle(f-I) z, J(y-z)\rangle \leq 0, \quad \forall y \in \operatorname{Fix}(T)
$$

Equivalently, $z=P f(z)$, where $P$ denotes the unique sunny nonexpansive retraction of $C$ onto $\operatorname{Fix}(T)$.

Proof Denote by $\mathbb{Z}_{+}=(\mathbb{Z},+)$ the semigroup of nonnegative integers. It is obvious that $\varphi=$ $\left\{T^{j}: j \in \mathbb{Z}\right\}$ is an asymptotically nonexpansive semigroup on $C$. For every $n \in \mathbb{Z}_{+}$and $f \in$ $l^{\infty}\left(\mathbb{Z}_{+}\right)$, define

$$
\mu_{n} f=\frac{1}{(n+1)^{2}} \sum_{j=0}^{\infty} f(j) .
$$

Hence $\left\{\mu_{n}\right\}_{n=1}^{\infty}$ is a strongly regular sequence of means on $l^{\infty}\left(\mathbb{Z}_{+}\right)$and $\lim _{n \rightarrow \infty} \| \mu_{n+1}-$ $\mu_{n} \|=0$ [28]. Further, for each $y \in C$, we have

$$
T_{\mu_{n}}=\frac{1}{(n+1)^{2}} \sum_{j=0}^{\infty} T^{j} y .
$$

By Theorem 3.1, $\left\{x_{n}\right\}_{n=1}^{\infty}$ and $\left\{y_{n}\right\}_{n=1}^{\infty}$ converge strongly to $z \in \operatorname{Fix}(T)$. This completes the proof.

Example 4.6 Let $C$ be a compact convex subset of a smooth Banach space $E$ such that $0 \in C$. Let $f$ be a contraction of $C$ into itself with constant $\alpha \in(0,1)$, let $\left\{\alpha_{n}\right\}_{n=1}^{\infty},\left\{\beta_{n}\right\}_{n=1}^{\infty}$ and $\left\{\gamma_{n}\right\}_{n=1}^{\infty}$ be sequences in $(0,1)$ satisfying conditions $\left(C_{1}\right)-\left(C_{4}\right)$, and let $\left\{\delta_{n}\right\}_{n=1}^{\infty}$ be a sequence 
in $(0,1)$ satisfying condition $\left(C_{5}^{\prime}\right)$. If $\left\{x_{n}\right\}_{n=1}^{\infty}$ and $\left\{y_{n}\right\}_{n=1}^{\infty}$ are sequences generated by $x_{1} \in C$ and

$$
\begin{aligned}
& y_{n}=\delta_{n} x_{n}+\frac{2\left(1-\delta_{n}\right)}{(n+1)^{2}} \sum_{j=0}^{(n+1)^{2}} \sqrt[n]{\left(1+\frac{1}{n \ln ^{2} n}\right)^{j}} x_{n}, \\
& x_{n+1}=\alpha_{n} f\left(y_{n}\right)+\beta_{n} x_{n}+\frac{2 \gamma_{n}}{(n+1)^{2}} \sum_{j=0}^{(n+1)^{2}} \sqrt[n]{\left(1+\frac{1}{n \ln ^{2} n}\right)^{j}} y_{n},
\end{aligned}
$$

then $\left\{x_{n}\right\}_{n=1}^{\infty}$ and $\left\{y_{n}\right\}_{n=1}^{\infty}$ converge strongly to $z \in C$.

Proof We define

$$
\begin{aligned}
& T: C \rightarrow C, \\
& T(x)=\sqrt[n]{\left(1+\frac{1}{n \ln ^{2} n}\right)} x .
\end{aligned}
$$

Obviously, $T$ is an asymptotically nonexpansive mapping with Lipschitz constants $l_{n}(T)=$ $\left(1+\frac{1}{n \ln ^{2} n}\right)$. Moreover,

$$
\sum_{n=0}^{\infty}\left(l_{n}-1\right)=\sum_{n=0}^{\infty}\left(1+\frac{1}{n \ln ^{2} n}-1\right)=\sum_{n=0}^{\infty} \frac{1}{n \ln ^{2} n}<\infty
$$

Therefore, applying Corollary 4.5, the result follows.

Remark 4.7 For deducing some more applications, we refer to [13, 19, 24, 25, 28, 30].

Remark 4.8 Theorem 3.1 improves and extends [4, Theorem 3.1] and [2, Theorem 3.1] in the following aspects.

(1) Theorem 3.1 extends [4, Theorem 3.1] and [2, Theorem 3.1] from one sequence of means to a finite family of sequences of means.

(2) In Theorem 3.1, by taking $T_{\mu_{i, n}}=I$ for $i=1,2, \ldots, m-1, T_{\mu_{m, n}}=T_{\mu_{n}}$ and $y_{m, n}=y_{n}$, one can see that [4, Theorem 3.1] is a special case of Theorem 3.1.

(3) In Theorem 3.1, by taking $T_{\mu_{i, n}}=I$ for $i=1,2, \ldots, m$, one can see that [2, Theorem 3.1] is a special case of Theorem 3.1.

(4) Theorem 3.1 gives all consequences of [4, Theorem 3.1] and [2, Theorem 3.1] without assumption $C_{5}$ used in [4, Theorem 3.1] and [2, Theorem 3.1].

The authors declare that there is no conflict of interests regarding the publication of this paper.

\section{Authors' contributions}

All authors contributed equally and significantly in writing this article. All authors read and approved the final manuscript.

\section{Author details}




\section{Acknowledgements}

The authors were supported by the Higher Education Research Promotion and National Research University Project of Thailand, Office of the Higher Education Commission (Grant No. NRU56000508).

Received: 11 August 2013 Accepted: 10 October 2013 Published: 22 Nov 2013

\section{References}

1. Lau, AT, Miyake, H, Takahashi, W: Approximation of fixed points for amenable semigroups of nonexpansive mappings in Banach spaces. Nonlinear Anal. 67(4), 1211-1225 (2007)

2. Saeidi, S: Approximating common fixed points of Lipschitzian semigroup in smooth Banach spaces. Fixed Point Theory Appl. 2008, Article ID 363257 (2008)

3. Zhang, SS, Yang, L, Liu, JA: Strong convergence theorems for nonexpansive mappings in Banach spaces. Appl. Math. Mech. 28, 1287-1297 (2007)

4. Katchang, P, Kumam, P: A composite explicit iterative process with a viscosity method for Lipschitzian semigroup in smooth Banach space. Bull. Iran. Math. Soc. 37, 143-159 (2011)

5. Kumam, P, Wattanawitoon, K: A general composite explicit iterative scheme of fixed point solutions of variational inequalities for nonexpansive semigroups. Math. Comput. Model. 53, 998-1006 (2011)

6. Kumam, P, Plubtieng, S, Katchang, P: Viscosity approximation to a common solution of variational inequality problems and fixed point problems for Lipschitzian semigroup in Banach spaces. Math. Sci. 7, 28 (2013)

7. Saewan, S, Kumam, P: Explicit iterations for Lipschitzian semigroups with Meir-Keeler type contraction in Banach spaces. J. Inequal. Appl. 2012, Article ID 279 (2012)

8. Sunthrayuth, $\mathrm{P}$, Wattanawitoon, K, Kumam, P: Convergence theorems of a general composite iterative method for nonexpansive semigroups in Banach spaces. ISRN Math. Anal. 2011, Article ID 576135 (2011)

9. Huang, Q, Zhu, L, Li, G: Fixed point theorems for left amenable semigroups of non-Lipschitzian mappings in Banach spaces. Fixed Point Theory Appl. 2012, Article ID 116 (2012). doi:10.1186/1687-1812-2012-116

10. Sunthrayuth, P, Kumam, P: A general iterative algorithm for the solution of variational inequalities for a nonexpansive semigroup in Banach spaces. J. Nonlinear Anal. Optim. 1(1), 139-150 (2010)

11. Sunthrayuth, $P$, Kumam, $P: A$ new composite general iterative scheme for nonexpansive semigroups in Banach spaces. Int. J. Math. Math. Sci. 2011, Article ID 560671 (2011)

12. Wattanawitoon, K, Kumam, P: Strong convergence to common fixed points for countable families of asymptotically nonexpansive mappings and semigroups. Fixed Point Theory Appl. 2010, Article ID 301868 (2010). doi:10.1155/2010/301868

13. Atsushiba, S, Takahashi, W: Strong convergence theorems for one-parameter nonexpansive semigroups with compact domains. In: Cho, YJ, Kim, JK, Kang, SM (eds.) Fixed Point Theory and Applications, vol. 3, pp. 15-31. Nova Science Publishers, New York (2002)

14. Lau, AT: Invariant means on almost periodic functions and fixed point properties. Rocky Mt. J. Math. 3, 69-76 (1973)

15. Lau, AT: Semigroup of nonexpansive mappings on a Hilbert space. J. Math. Anal. Appl. 105(2), 514-522 (1985)

16. Agarwal, RP, O'Regan, D, Sahu, DR: Fixed Point Theory for Lipschitzian-Type Mappings with Applications. Topological Fixed Point Theory and Its Applications, vol. 6. Springer, New York (2009)

17. Kim, KS: Nonlinear ergodic theorems of nonexpansive type mappings. J. Math. Anal. Appl. 358, 261-272 (2009)

18. Holmes, RD, Lau, AT: Non-expansive actions of topological semigroups and fixed points. J. Lond. Math. Soc. 5, 330-336 (1972)

19. Takahashi, W: Nonlinear Functional Analysis: Fixed Point Theory and Its Applications. Yokohama Publishers, Yokohama (2000)

20. Lau, AT, Shioji, N, Takahashi, W: Existence of nonexpansive retractions for amenable semigroups of nonexpansive mappings and nonlinear ergodic theorems in Banach spaces. J. Funct. Anal. 161(1), $62-75$ (1999)

21. Kim, KS: Convergence of a hybrid algorithm for a reversible semigroup of nonlinear operators in Banach spaces. Nonlinear Anal. 73(3), 3413-3419 (2010)

22. Reich, S: Asymptotic behavior of contraction in Banach spaces. J. Math. Anal. Appl. 44, 57-70 (1973)

23. Xu, HK: An iterative approach to quadratic optimization. J. Optim. Theory Appl. 116(3), 659-678 (2003)

24. Piri, H: Hybrid pseudo-viscosity approximation schemes for systems of equilibrium problems and fixed point problems of infinite family and semigroup of non-expansive mappings. Nonlinear Anal. 74, 6788-6804 (2011)

25. Piri, $\mathrm{H}$, Badali, $\mathrm{AH}$ : Strong convergence theorem for amenable semigroups of nonexpansive mappings and variational inequalities. Fixed Point Theory Appl. 2011, Article ID 55 (2011)

26. Brézis, H, Browder, FE: Nonlinear ergodic theorem. Bull. Am. Math. Soc. 82, 959-961 (1976)

27. Brézis, H, Browder, FE: Remark on nonlinear ergodic theory. Adv. Math. 25, 165-177 (1977)

28. Eshita, K, Miyake, H, Takahashi, W: Strong convergence theorems for asymptotically nonexpansive mappings in general Banach spaces. Dyn. Contin. Discrete Impuls. Syst., Ser. A Math. Anal. 13, 621-640 (2006)

29. Lorentz, GG: A contribution to the theory of divergent series. Acta Math. 80, 167-190 (1948)

30. Hirano, N, Kido, K, Takahashi, W: Nonexpansive retractions and nonlinear ergodic theorems in Banach spaces. Nonlinear Anal. 28, 1269-1281 (1988)

31. Reich, S: Nonlinear evolution equations and nonlinear ergodic theorems. Nonlinear Anal. 1, 319-330 (1977)

32. Reich, S: Almost convergence and nonlinear ergodic theorems. J. Approx. Theory 24, $269-272$ (1978)

33. Miyake, H, Takahashi, W: Nonlinear mean ergodic theorems for nonexpansive semigroup in Banach spaces. J. Fixed Point Theory Appl. 2, 360-382 (2007) 